Article

\title{
Sustainability Analysis of Fish Feed Derived from Aquatic Plant and Insect
}

\author{
Shashank Goyal ${ }^{1, *}$, Denise Ott ${ }^{1}{ }^{\mathbb{C}}$, Jens Liebscher ${ }^{2}$, Dennis Höfling ${ }^{2}$, Ariane Müller ${ }^{3}$, Jens Dautz ${ }^{4}$, \\ Herwig O. Gutzeit ${ }^{3}$, Dirk Schmidt ${ }^{1}$ and Rosmarie Reuss ${ }^{1}$ \\ 1 EurA AG, 73479 Ellwangen, Germany; denise.ott@eura-ag.de (D.O.); dirk.schmidt@eura-ag.de (D.S.); \\ rosmarie.reuss@eura-ag.de (R.R.) \\ 2 Bio.S Biogas GmbH Beiersdorf, 04668 Grimma, Germany; liebscher@bios-biogas.de (J.L.); \\ dennis.hoefling@madebymade.eu (D.H.) \\ 3 Institut für Zoologie, TU Dresden, 01069 Dresden, Germany; aradam@msx.tu-dresden.de (A.M.); \\ herwig.gutzeit@gmail.com (H.O.G.) \\ 4 Terra Urbana GmbH Zossen, 15806 Zossen, Germany; jdautz@terraurbana.de \\ * Correspondence: shashank.goyal@eura-ag.de
}

Citation: Goyal, S.; Ott, D.; Liebscher, J.; Höfling, D.; Müller, A.; Dautz, J.; Gutzeit, H.O.; Schmidt, D.; Reuss, R. Sustainability Analysis of Fish Feed Derived from Aquatic Plant and Insect. Sustainability 2021, 13, 7371. https://doi.org/10.3390/su13137371

Academic Editor:

Francesco Tiralongo

Received: 3 May 2021

Accepted: 25 June 2021

Published: 1 July 2021

Publisher's Note: MDPI stays neutral with regard to jurisdictional claims in published maps and institutional affiliations.

Copyright: () 2021 by the authors. Licensee MDPI, Basel, Switzerland. This article is an open access article distributed under the terms and conditions of the Creative Commons Attribution (CC BY) license (https:// creativecommons.org/licenses/by/ $4.0 /)$.

\begin{abstract}
Fish and meat production and processing will grow drastically in the coming decades. In aquacultural systems, insects are gaining interest as feed to provide a sustainable alternative to the fishmeal paradox, whose production leads to high consumption of resources and negative environmental impacts. Within the scope of this study, the production of fish feed from Hermetia illucens larvae and Lemna minor in an inline recirculating aquaponics model for urban sites was developed and optimized, which efficiently combines waste and environmental service concepts in one production system. At the same time, the value chain produces high-quality, market-accessible raw materials for the fish feed industry. All investigations were accompanied by a comparative Life Cycle Assessment (LCA) to measure and compare ecological effects to finally result in sustainable alternatives. The results achieved in this research show that fish feed based on Hermetia illucens and Lemna minor can have the potential to be ecologically competitive or more sustainable than standard feed. It should be noted that the comparison here represents the results of the project on a pilot scale. Various optimization potentials were shown, which are essential for the large-scale implementation of the breeding of both species as well as their processing up to the fish feed pellets.
\end{abstract}

Keywords: Hermetia illucens; Lemna minor; fish feed; tilapia; life cycle assessment

\section{Introduction}

Aquaculture is a centuries-old activity that has developed gradually, frequently by expanding on traditional information, progress acquired through farmers' interests, needs, positive experiences, and mistakes, or collaboration. Subsequently, it has extended for a long time, incorporated with its natural, social, financial, and cultural environments. The outcome in terms of development has been extraordinary, and aquaculture presently supplies the greater part of the world's fish for human utilization [1].

However, there have additionally been unwanted ecological effects at the local, regional and worldwide levels. These adverse impacts incorporate social conflicts between land users and water resources and the obliteration of significant ecosystem services. Besides, recent aquaculture endeavors have raised concerns and societal discussions, particularly concerning poor site determination; the utilization of destructive chemical compounds and veterinary medications; inefficient or unsustainable production of fishmeal and fish oil; and social and cultural effects on aquaculture laborers and communities [2]. Numerous sustainability challenges have become progressively reducing and new ones have arisen, which put human well-being, economic prosperity, our general public, and the environment in danger. To confront these challenges and advance towards a sustainable Europe by 
2030, the EU has recognized a set of key policy foundations, which should be additionally fortified, and enablers that should be equipped towards the sustainability change.

Excess utilization of sea resources has brought a quick development in aquaculture because of its capability to alter the course from depletion. Closed system aquaculture is considered one of the more environmentally benign methods of rearing aquatic species [3]. There are certain controversies associated with the ecological performance of aquaculture. In this context, a broad analysis must be performed to explore the sustainability of aquaculture. As a tool to evaluate the environmental performance of aquaculture, LCA has often been used [4-6]. LCA as a methodology is aimed at analyzing the ecological aspects and potential impacts associated with a service or a product by compiling the input-output inventory of the process, calculating environmental burdens associated with those input-output and finally interpreting the results of impact assessment corresponding to the aim of the study $[7,8]$. The comprehensive nature of LCA makes it suitable for providing transparency to the production chains $[9,10]$.

The studied fish feed itself is an innovation by combining Lemna minor (henceforth referred to as LM) and Hermetia illucens (larvae) (henceforth referred to as BSFL). It is known that the BSFL meal is a good source of protein and have the potential to replace fish protein [11,12]. However, the high lipid content impairs pure utilization by fish. The duckweed meal, LM, on the other hand, offers a lipid content of no more than $10 \%$ (of dry matter) [13] and a high protein content of around $40 \%$ depending on the growing conditions [14,15]. In addition, LM is characterized by very rapid growth (short doubling times) and thus a rapid increase in biomass. The development of sustainably produced and optimized fish feed from BSFL and LM meal, therefore, offers several key advantages.

LM is a little, floating plant. It spreads openly and is generally discovered growing in colonies that can cover very large areas of still water. The plant is accumulated from the wild for local use as food and medicine. It very well may be an inconvenient lake weed however it is easily constrained by just scooping it out $[16,17]$. This scooped-out material makes an amazing addition to the fertilizer. This growing plant is a decent food hotspot for fish and birds, as well as giving cover to the creatures in the pond [17].

The black soldier fly is a common and widespread fly of the family Stratiomyidae. The larvae have an insatiable hunger and can be utilized for composting food waste and agricultural waste products. Moreover, BSFL is an alternative source of protein for aquaculture, animal feed, pet food, and human nutrition $[18,19]$. BSFL is utilized to compost waste or convert the waste into animal feed. BSFL are among the most productive animals at changing feed into biomass. The reaped pupae and prepupae are eaten by poultry, fish, pigs, reptiles, turtles, and even dogs $[20,21]$. The BSFL is one of the few insect groups endorsed to be utilized as feed in aquaculture in the EU [22].

The production of LM and BSFL meal does not require significant land use due to the in-line culture system. An in-line system is a system in which the production happens repetitively, and the process is not stopped (like a continuous system). Furthermore, a resource-saving and energy-efficient production process is developed, and the resulting innovative fish feed thus fulfills the demands placed on a sustainable economy. By using different mixing ratios of BSFL and LM meal, the feed can be optimized and adapted to specific species. This LCA study aims to identify ecological drivers for the development and manufacture of novel protein-rich feed based on LM and BSFL meal, to make pioneering recommendations, and finally to carry out a comparison to benchmark feed based on fish meal. The scope of the study was chosen based on the goal and included the level of detail, systems and processes, functional units, system boundary, impact categories, interpretation methods, and allocation methods.

To date, many LCA studies are dealing with different fish species and aquaculture. On one side, the studies on extensive aquaculture majorly dealt with mussel culture [6,23-25] while on the other side, studies on intensive aquaculture dealt majorly with different kinds of fish species. A common conclusion drawn from the environmental assessment of intensive aquaculture is the leading role played by fish feed $[4,5]$. This study focuses 
on the LCA of feed production. Furthermore, the feed considered in this LCA study is for tilapia (Oreochromis niloticus) fish in Germany and is compared to conventional tilapia feed to evaluate the ecological impact of the feed.

\section{Materials and Methods}

The materials considered for the formulation of fish feed are LM and BSFL. LCA was chosen as the methodology and was performed within the framework of the International Organization for Standardization (ISO) 14040 and 14044 [7,8]. The analysis of aquafeed was carried out cradle-to-gate, i.e., from the cradle (exploration of the raw materials) to the production of the individual components (LM and BSFL) for the manufacture and use of the compound feed. The pellets thus produced are referred to as LH pellets in the article herein. The functional unit chosen for the ecological comparison was made on the mass basis (e.g., $1 \mathrm{~kg} \mathrm{LH}$ pellets vs. $1 \mathrm{~kg}$ Tilapia feed), since a similar protein and fat content was found. The system boundary considered in this study is shown in Figure 1. The energy utilized in this study was taken from a biogas plant which was installed near the container where insects were rearing. This served as an advantage from the perspective of ecological impacts. The life cycle inventory and impact assessment method are illustrated in the following subsection.

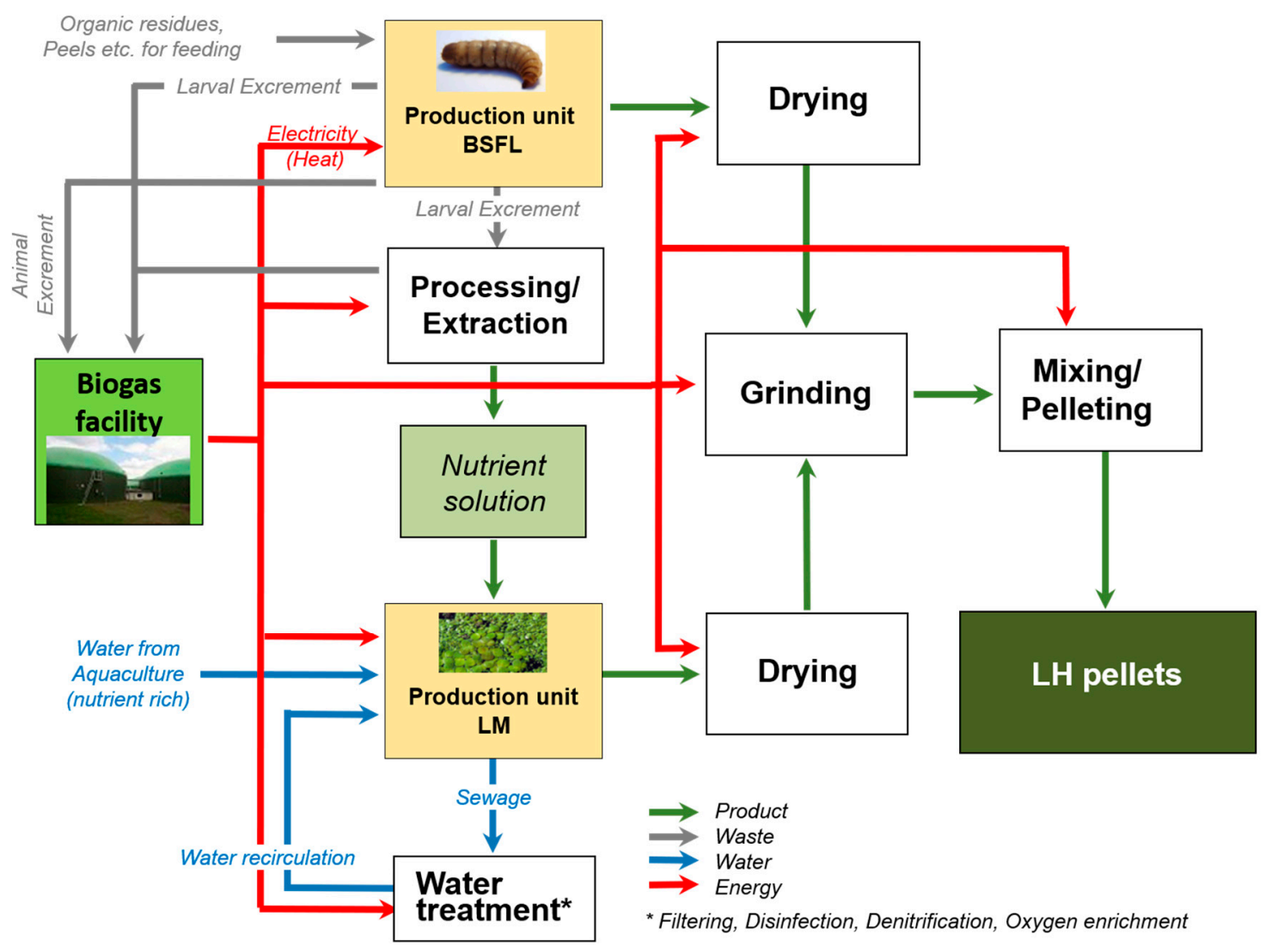

Figure 1. System boundary and material flow.

\subsection{Experimental Set-Up}

BSFL were produced and reared on organic and peeling waste in the black soldier fly pilot plant in Saxony, Germany, linked to a biogas plant. Late larvae and prepupae were separated from larval excrements (feces) by a vibrating sieve and dried in a drying oven.

LM starting culture plants were purchased from NatureHolic GmbH. Precultures were grown in the laboratory on half concentrated Schenk \& Hildebrand media in flat plastic trays next to glass windows at room temperature. They were transferred to the pilot tanks in the designed LM pilot plant in Saxony, Germany, which was also linked to the biogas 
plant. The fertilizer was autoclaved larval feces solution ( $400 \mathrm{~g}$ larval faeces $/ 51 \mathrm{dH}_{2} \mathrm{O}$ ). Depending on growth performance, LM plants were harvested and dried in a drying oven. $50 \%$ of LM is harvested and the remaining $50 \%$ serves as the base for the next cultivation cycle.

For making LH pellets, shredding of the starting material occurred using a roller mill, using gap size zero for LM and 0.75 for BSFL. LH pellets were pressed using a pelleting machine with a $5 \mathrm{~mm}$ perforating matrix in ratio 1:1 and 2:1.

Circular-inline-production cycle. The existing biogas plant supplied excess heat and energy to produce BSFL and LM. The established black soldier fly production unit produced BSFL and larval feces, which were used as fertilizer in the newly established LM production unit. BSFL and LM were grinded and pelleted and fish feeding trials were performed using Oreochromes niloticus (see Figure 1).

\subsection{Life Cycle Inventory}

As part of the life cycle inventory data collection, questionnaires were designed in which all material and energy flows (breeding containers, equipment, consumables, energy requirements for cooling, dehumidification, processing, transport processes, etc.) by the project partners qualitatively and quantitatively as the basis of the ecological (as well as economic) analysis were recorded. Besides, data from product data sheets were used, for example concerning the composition of the disinfectant used. Due to confidentiality reasons, the entered life cycle inventory data cannot be published. A sample questionnaire (blank) is added in the Supplementary Material Section to know about all the data that was collected as a part of the life cycle inventory.

The modeling of the material and energy flows in the context of this study was carried out with the help of the computer application GaBi. With the help of the integrated Ecoinvent 3.5 database, corresponding inventory data regarding the provision of raw materials, materials, energy, or transport processes were integrated. A lifespan of 50 years was assumed for the container system, a lifespan of 10 years for the other equipment (containers, piping, seals, air filter, protective coating, etc.), and a lifespan of 5 years for LED lamps which served as the pilot-scale facility for the production of LM and BSFL.

\subsection{Impact Assessment}

The impact assessment was carried out according to ReCiPe 2016 v1.1 with the help of midpoint indicators at the hierarchical level. The time horizon of the impact assessment is 100 years. All impact potentials were considered, but the impact categories for the evaluation within the scope of this study are climate change (hereinafter also referred to as "greenhouse potential", climate change, unit: $\mathrm{kg} \mathrm{CO}_{2}$ equivalents per functional unit), primary energy consumption (unit: MJ per functional unit), land consumption (Unit: $\mathrm{m}^{2} \mathrm{a}$ per functional unit) and water consumption or footprint (unit: $\mathrm{m}^{3}$ freshwater per functional unit). These are of particular importance in the context of the production of sustainable animal feed. There were no deviating results or trends when considering the other impact categories. The impact categories were not weighted.

The functional unit (FU) is defined by ISO standards as a quantified performance of a product system to be used as the reference unit in an LCA study $[7,8]$. The FU for the LCA of fish feed production was $1 \mathrm{~kg}$ LH pellets.

\section{Results and Discussion}

\subsection{BSFL Production Results}

The environmental impact assessment of BSFL production was carried out in several phases, aiming to accompany the $R \& D$ activities to derive recommendations before scaleup (Figures 2-4). When cereal bran was considered as the feed for insects, more than $50 \%$ of the environmental impacts were because of cereal bran (Figure 2). To make insect production more sustainable, insects were then fed with organic waste (according to the EU Regulation) [26] and the change in result could be seen in Figure 3. Another driver of 
the environmental impacts is the energy requirement (for maintaining the temperature inside the container) in the production of insects as also observed in the study from Smetana et al., 2016 [27]. However, in this study, the energy used is taken from a biogas plant which is installed in the vicinity of the container where insects are rearing. This is clearly an advantage from the perspective of environmental impacts compared to heat generated by non-renewable sources of energy as also investigated by Fusi et al., 2016 [28]. Additionally, if the energy arising in the biogas plant would be considered as "waste energy", as for now no dedicated purpose of it was foreseen at the manufacturing site, the environmental burdens could get further reduced, revealing new ecological drivers (see Figure 4). Such ecological drivers are cleaning agents, sawdust used for breeding, and electricity from the biogas plant. Hence, there is still potential for further optimization. One example of such optimization is the sawdust which can be used several times and finally serve as feed for the biogas plant, making an environmental benefit. The container used for insect breeding is not fully utilized which could also lower the share of energy requirement. The emissions (dark green bar in Figure 4) in the category of "greenhouse gas potential" describe a "worst-case" scenario: as no real-life emission data (methane, nitrous oxide, and ammonia) was available, the data for the emission of gases from breeding BSFL with manure as feed was taken from the literature [29].

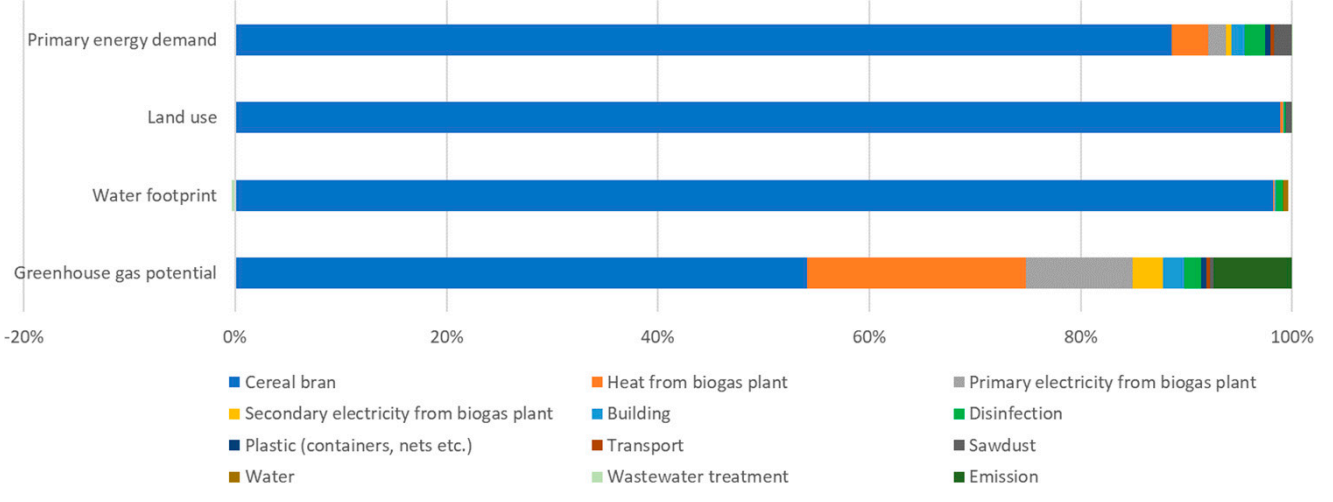

Figure 2. Relative environmental impacts during the production of per $\mathrm{kg}$ BSFL while feeding them cereal bran.

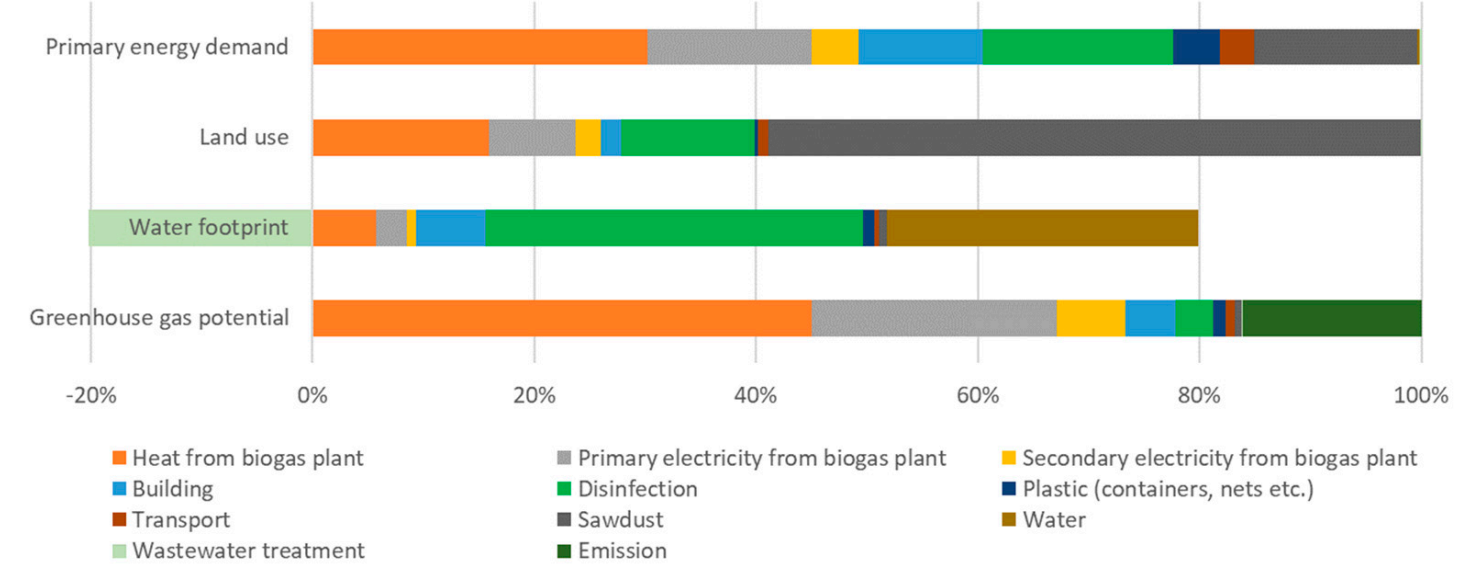

Figure 3. Relative environmental impacts during the production of per $\mathrm{kg}$ BSFL while feeding them food waste.

Many environmental impact assessment studies on insect breeding have shown that high ecological impacts are because of feed and energy requirements [27,30-33] as also identified and addressed within our study. Hence, the use of a secondary source of energy and raw materials within the scope of this study leads to an overall reduction of up to $70 \%$ in environmental impacts during BSFL production. 
Furthermore, drying, grinding and pelleting of larvae were assessed. It was assumed that all the processing activities took place at one location and the electricity consumed for the processing will be from the biogas plant. The environmental impacts of the machines (oven for drying, grinder, pelletizer) were not considered. The assumption for grinding was considered from the Ecoinvent dataset "market for oil mill", and the resulting ecological impacts were negligible. This justifies the assumption made due to the lack of availability of information. The red bar in Figure 5 shows the environmental impact contribution of processing BSFL. The water footprint of larvae processing is negative because the drying of larvae release water. This released water in the form of vapor is assumed to be used again (theoretically) for cleaning purposes. Due to the high requirement of energy, in order of drying > grinding > pelleting, the impact of larvae processing in the BSFL production chain is up to $20 \%$ (see global warming potential in Figure 5). The drying process needs to be further optimized to reduce the ecological burden. This could be done by optimal use of drying oven, use of waste heat from biogas plant for oven, heat recovery, etc, being part of future scale-up activities.

$\mid$

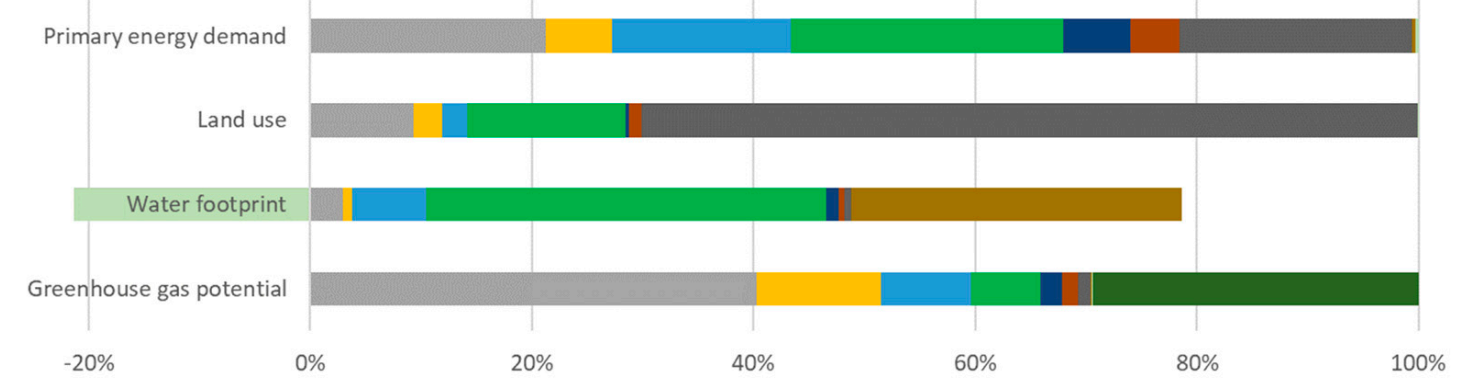

- Primary electricity from biogas plant
Disinfection
— Sawdust
— Emission

- Secondary electricity from biogas plant - Plastic (containers, nets etc.)

Water

- Building

- Transport

Wastewater treatment

Figure 4. Relative environmental impacts during the production of per kg BSFL, assuming no ecological burden of heat generated in the biogas plant.

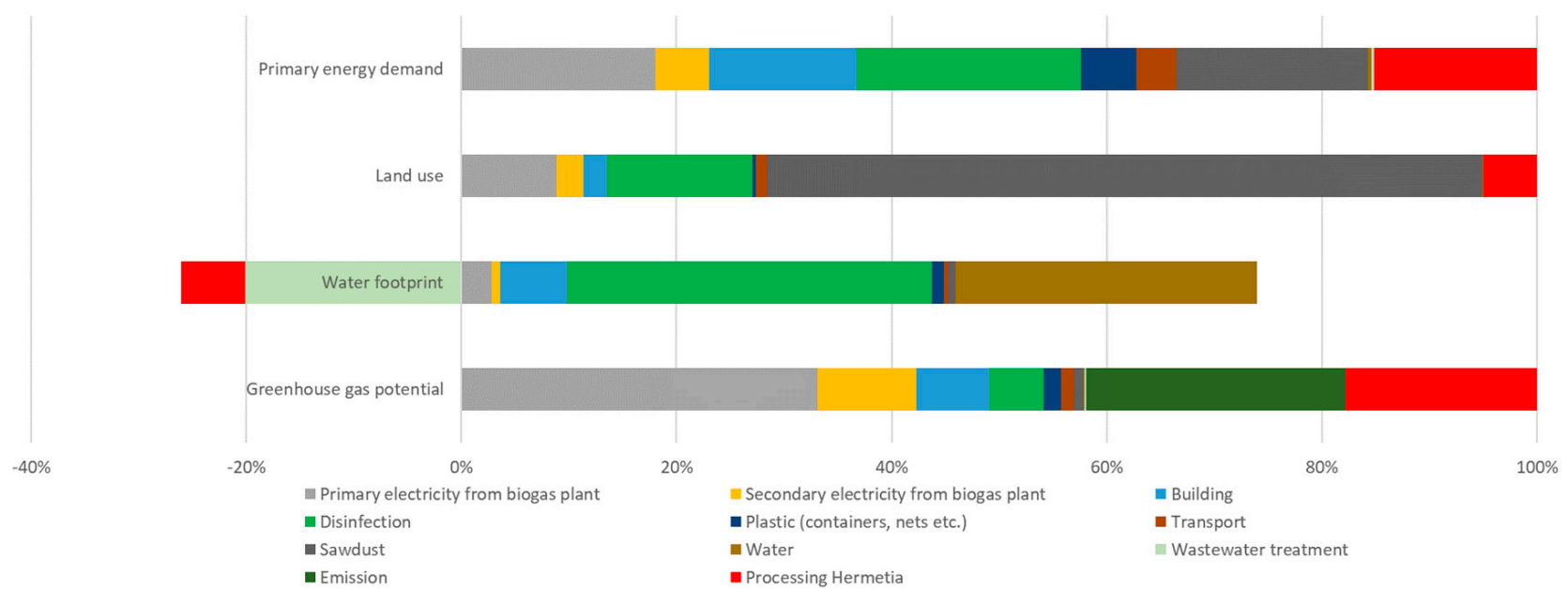

Figure 5. Relative contribution in environmental impacts during the production and processing of $1 \mathrm{~kg}$ of BSFL.

\subsection{LM Production Results}

The optimization of the LM breeding condition and the associated environmental impact was carried out at the pilot scale, i.e., in a container facility. The different components (pipes, filters, trays, pumps, lamps, dehumidifiers, etc.) used for the establishment of the 
container for LM breeding were considered as precisely as possible according to the list provided by the company responsible for establishing the container. An initial evaluation was made with the yield obtained by supplying LM cultures with BSFL excreta. In this case, the yield obtained was $1.142 \mathrm{~kg} /$ day $\left(45.71 \mathrm{~g} / \mathrm{m}^{2} \mathrm{~d}\right)$ fresh mass which did not correspond to the aim specified in the project proposal and the assessment of ecological impacts did not justify LM cultivation so far. This result was due to the insufficient nutritional content of feces, which needs to be a subject of investigation in the near future. To optimize this temporarily, standard fertilizer (Flora Series manufactured by Terra Aquatica, Fleurance, France) was then used for LM cultivation. The resultant yield after the use of standard fertilizer was $2.85 \mathrm{~kg} /$ day $\left(114.3 \mathrm{~g} / \mathrm{m}^{2} \mathrm{~d}\right)$ fresh mass.

The contribution of individual components of LM cultivation towards the environmental impacts is shown in Figure 6. The impact of fertilizer dominates in all the considered environmental indicators (primary energy demand, land use, water footprint, and greenhouse gas potential). The fertilizer was added as per "direction to use" given by the provider, however, this has the potential to optimize for reducing the environmental burden. The trays for LM cultivation were cleaned and refilled every six months (earlier in case of heavy algae growth etc.). The water after cleaning and older water goes to the wastewater treatment plant. However, this water is rich in nutrients and can recirculate in the scale-up production plant. Furthermore, our concept has foreseen the use of feces instead of artificial fertilizer. Its optimization, i.e., by adapting the food given to BSFL, is an urgent subject of an investigation to reduce the overall environmental burdens of LM rearing.

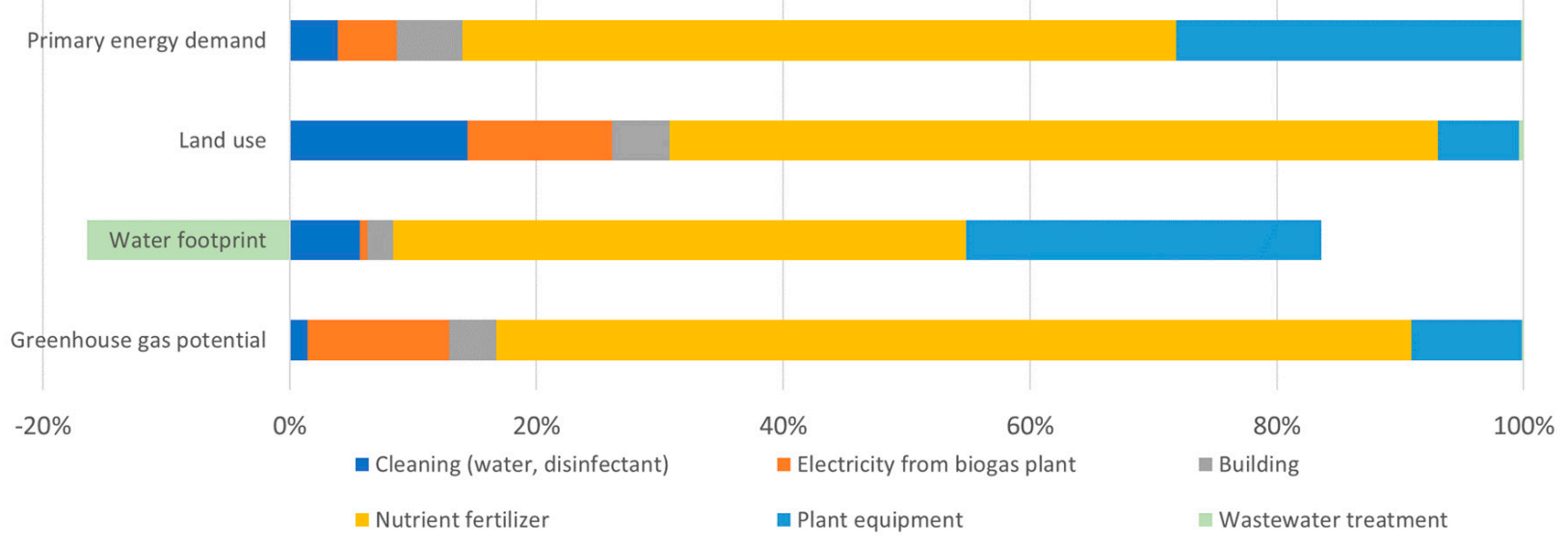

Figure 6. Relative contribution of environmental impacts in the production of $1 \mathrm{~kg}$ fresh LM using artificial fertilizer.

Under the category of "Plant equipment", there are many components such as pipes, filters, etc. out of which plastic (used for different pipes, trays, etc.) imposes a greater threat to the environment. Other technical equipment such as pumps, lamps, dehumidifiers were also considered although their calculated environmental impacts were negligible. For the life cycle inventory of LED lamps, data of ultraviolet lamps from the ecoinvent database was assumed. The influence of these lamps on the environment for the entire life cycle (5 years in this case) came to be negligible. Despite having negligible environmental impacts, the efficient recycling of such lamps is very important as also concluded by Rebello et al., 2020 [34]. There are only a few recycling centers worldwide that work on the management of e-waste.

The relative contribution of environmental impacts in Figure 6 will show a drastic change if the electricity mix from Germany is used instead of electricity from the biogas plant (see Figure 7). This change of electricity from electricity mix to biogas plant results in the reduction of environmental impacts of all considered categories by a factor of 2 and the dominant category was electricity. However, these results depend on the geographical location of the study as well as the feed for the biogas plant. The energy consumption 
for the production of LM, in the decreasing order, is air-conditioning of room > water pump circuit $>$ lighting. During the winter season, the container for LM production could be heated using the heat from the biogas plant. For the assessment of the container, it is assumed that the temperature inside the container will be maintained electrically.

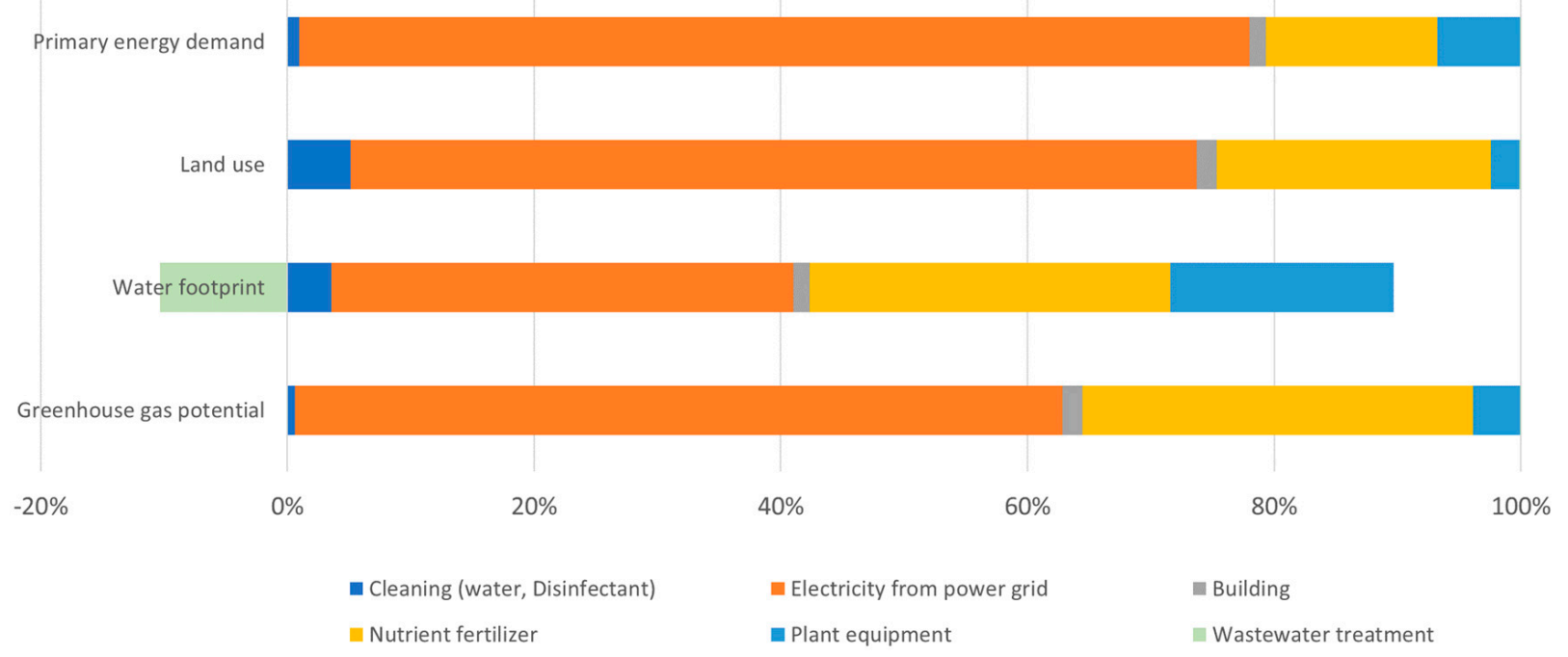

Figure 7. Relative contribution of environmental impacts during the production of $1 \mathrm{~kg}$ fresh LM using artificial fertilizer and energy from electricity mix of Germany.

Furthermore, the next steps for the processing of LM for feed purpose were assessed. Since the fresh mass of LM contains $90 \%$ water, therefore the efforts to produce $1 \mathrm{~kg}$ of dry will be 10 times that of fresh LM. Additionally, there is an energy requirement for the drying of fresh LM. To get a first insight into the ecological competitiveness of LM meal, it was compared to soy as both have a comparable nutritional profile and soy is also used for conventional fish feed production. The comparison of relative environmental impacts between $1 \mathrm{~kg}$ LM flour and soy flour is shown in Figure 8. Despite the fact that a direct comparison is difficult due to different scale of production so far, the results show (i) that LM is already competitive w.r.t. land use, and (ii) the importance of further optimization activities to reduce the ecological impacts of LM cultivation. In this context, LM yield is the key to success, which could be maximized by optimizing the cultivation parameters, use of fertilizers, and harvesting procedure. Currently, as soon as the LM tray is fully covered, $50 \%$ of it is harvested and the remaining 50\% serves as the base for the next cultivation cycle. Experiments are currently running to optimize the harvesting procedure.

\subsection{Result of Pellets (Derived from LM and BSFL) as Feed and Its Comparison to Conventional Feed}

Finally, the pellets (with different proportions of LM and BSFL) were evaluated and compared with a conventional feed. An optimal size of $2-4.5 \mathrm{~mm}$ of the feed behaves dimensionally stable in water over a longer period. Due to the nature and behavior of the feed in the water, it was consumed more quickly by the tilapia. The rapid breakdown of the pellets in water also increased the particle and particulate density in the tank. Despite the high suspended particle load and the high clogging of the filters every 2-3 days, the quality of the water was better than with the substitution of the control feed. In the olfactory quality determination, the feed under test with its only two ingredients LM and BSFL was described as much more pleasant. The different compositions of pellet, in terms of LM and BSFL, are presented in Table 1. As a benchmark for comparison, standard trout fish feed ( $41.5 \%$ crude protein; $22 \%$ crude fat) is considered. The composition of Pellet 1 and Pellet 2 would be similar to standard feed which is commercially available in the market in terms of protein and fat content. 


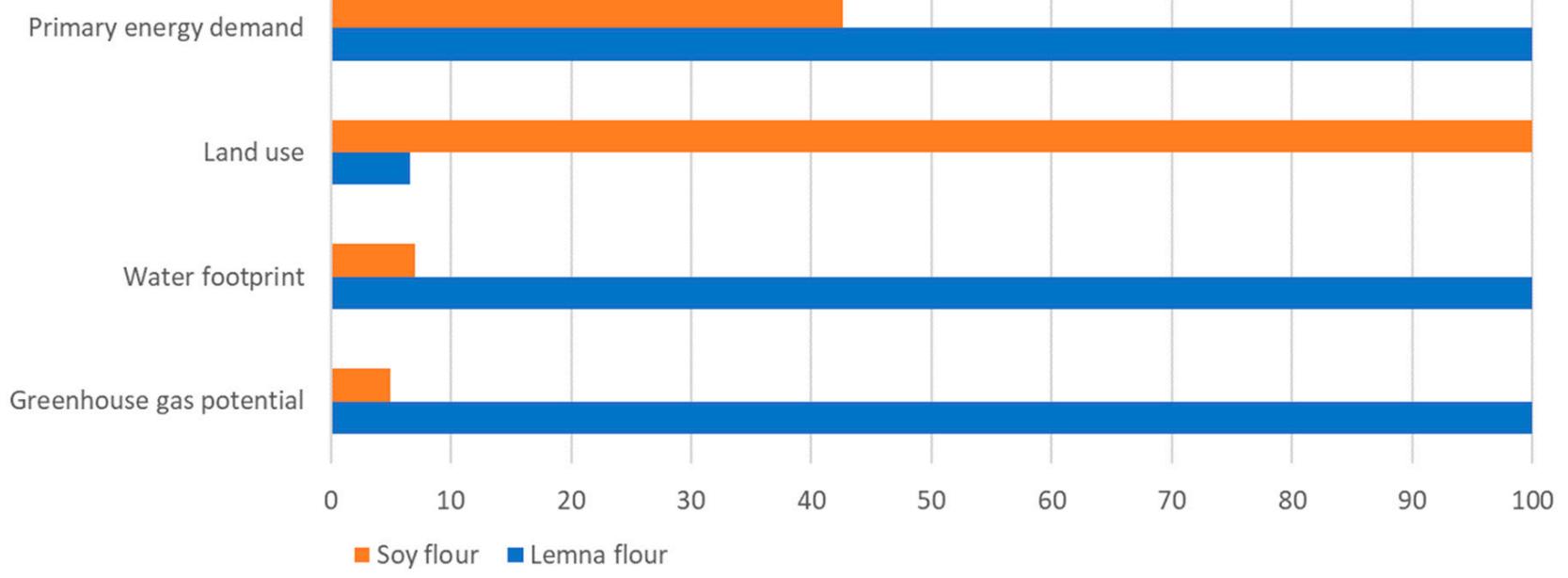

Figure 8. Relative contribution on environmental impacts during the production of LM flour and soy flour (1 kg each).

Table 1. Different LM \& BSFL composition for pellet scenarios.

\begin{tabular}{cccc}
\hline $\begin{array}{c}\text { Pellet } \\
\text { Scenario }\end{array}$ & $\begin{array}{c}\text { Percent } \\
\text { LM }\end{array}$ & $\begin{array}{c}\text { Percent } \\
\text { BSFL }\end{array}$ & Fish Feed Characteristic \\
Pellet 1 & 50 & 50 & $\begin{array}{c}\text { Protein content-36\% } \\
\text { Fat content-20\% } \\
\text { Protein content-38.4\% } \\
\text { Fat content-26\% } \\
\text { Pellet 2 }\end{array}$ Protein content-33.6\% \\
Fat content-14\%
\end{tabular}

Figure 9 shows the result based on mass, i.e., a comparison of $1 \mathrm{~kg}$ pellets each. In comparison to the BSFL production, LM production is currently much more ecologically complex. This could be seen by the increased environmental impact of Pellet 3 . The environmental sustainability decreases in the order Pellet $2>$ Pellet $1>$ Pellet 3 . From an ecological perspective, pellets with a composition of 30\% LM and 70\% BSFL (Pellet 2) are preferred. Optimizing LM production would have a significant impact on the ecological performance of the feed (depending on the potential and scenarios, a reduction of up to $30 \%$ is possible).
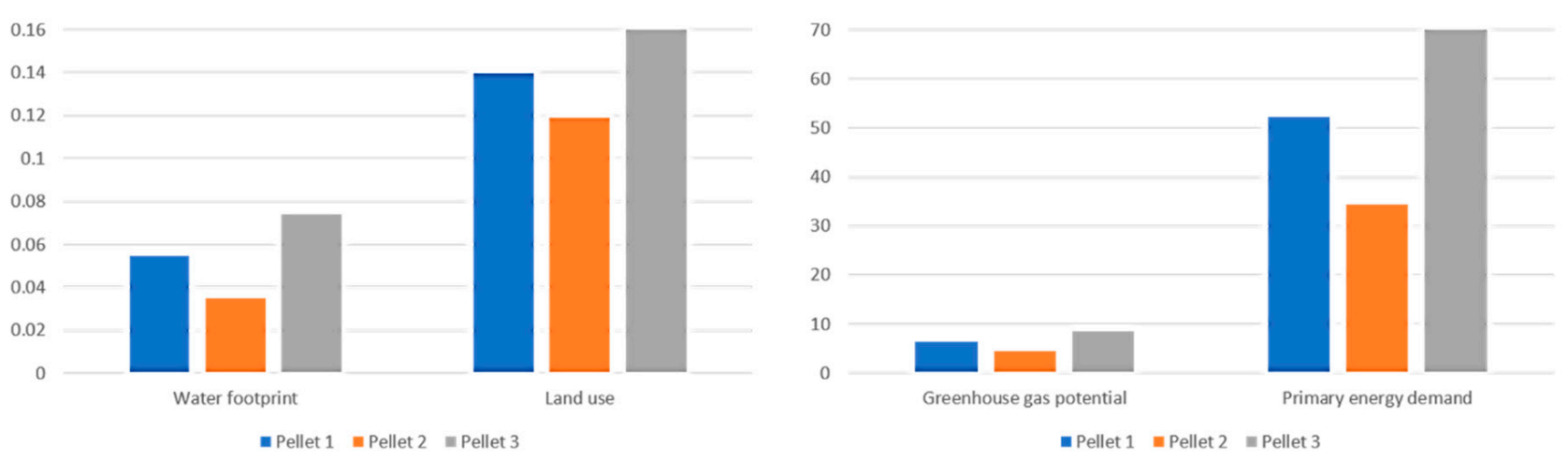

Figure 9. Relative comparison of environmental impacts during the production of $1 \mathrm{~kg}$ pellets with different composition (scenario description is in Table 1).

At the time when the environmental assessment was carried out, there was no conclusive data regarding the feeding attempts and feed performance on fish (acceptance of feed by fish, growth of fish, muscle protein, deficiency symptoms, health, etc.). To incorporate 
these effects, a variation of $\pm 50 \%$ in impact for Pellet $1-3$ was assumed while doing the comparison with standard fish feed as shown in Figure 10. This assumption will cover possible positive as well as negative performance results which could arise due to lack of information/data. For comparison, the Ecoinvent dataset [35] "Tilapia feed 24-28\% protein" and "Trout feed $42 \%$ protein" were used as a reference. It is assumed that the feeding rate was the same in each case $(0.74 \mathrm{~g} / \mathrm{d}$ per fish) according to the feeding plan. In Figure 10, the values of environmental impacts are normalized against the worst-case results per impact category and show a comparison based on the functional unit of $1 \mathrm{~kg}$ of fish feed.

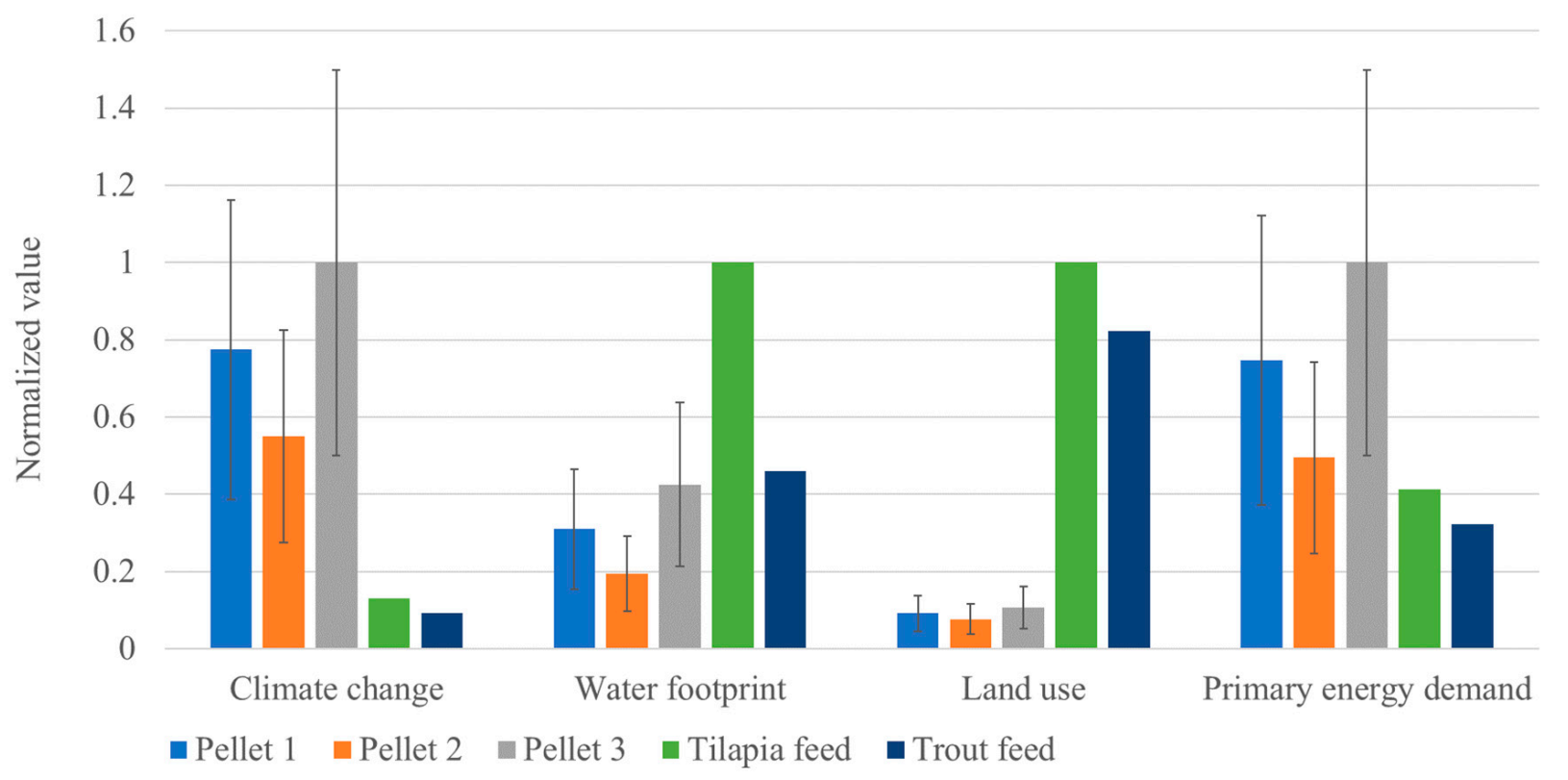

Figure 10. Relative comparison of environmental impacts during the production of $1 \mathrm{~kg}$ of pellets.

Irrespective of the LH pellet composition, there is already an ecological benefit regarding the category of water consumption and land use. The composition of both fish feed which are considered as the reference is taken from the Ecoinvent database and is shown in Figure 11. Contrary to the assumption, the contribution of fish meal and fish oil on environmental impacts was very small. Commonly, life cycle assessment methods and associated inventory datasets for sustainability assessment lack to incorporate ecological impacts of overfishing. Such studies, as also seen in the review article by Ruiz-Salmon et al., 2021 [36], focus only on fish processing to produce either fish meal or fish oil. This makes a holistic comparison difficult.

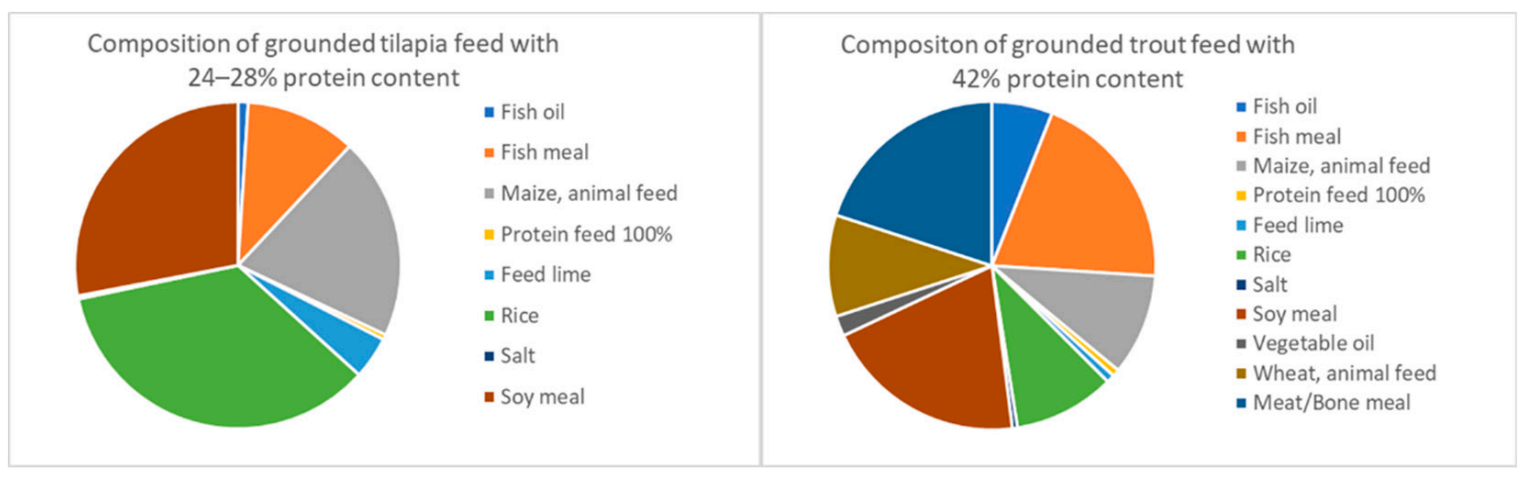

Figure 11. Tilapia and trout feed composition, data according to Ecoinvent. 


\section{Conclusions and Outlook}

The results achieved in this study show that fish feed based on LM and BSFL could potentially be more environmentally friendly than standard feed. It is important to note that these comparisons are based on results obtained from a pilot-scale study. Many optimization potentials exist which are important for the scale-up implementation of the breeding of both species (LM and BSFL). Such optimization potentials include efficient use of available space, development of an energy-efficient drying process, optimizing the quality and quantity of fertilizer, optimization of harvesting procedure, etc.

It is difficult to compare the results of this life cycle assessment study with the existing literature because the feeds analyzed in this study are different than the feeds in the literature. Plant-based fish feed is ecologically competent when compared to the feeds in literature having a high proportion of marine components (fish remains, wild fish) and other feeds with high grain (soy, etc.) content [37,38].

Apart from the fish feed, other business cases will also be developed as result of the running plant. There are many areas of application of LM and its advantages explored by different researchers. Mohedano et al. reported LM as a very successful floating macrophyte for the phytoremediation of organic pollutants [39]. Bonnao et al. examined the removal of different heavy metals using different macrophytes in a wetland receiving industrial and domestic effluents and reported that LM recorded the highest removal rate among the different macrophytes [40]. Olette et al. reported the successful application of LM for the remediation of pesticides [41]. Matamoros et al. found the successful application of LM in the phytoremediation of pharmaceuticals [42]. Ergen and Tunca evaluated the remediation of zinc oxide nanoparticles by LM and reported $98.60 \%$ removal efficiency [43]. Several other applications have been reviewed by Ekperusi and his group [44].

The manure of black soldier fly can be used as high-quality organic fertilizer as well, featuring balanced nitrogen, phosphate and potassium values. A generic environmental comparison between insect manure and synthetic fertilizer gives a positive outlook (see Figure 12). For this comparison, the following assumption was made: the nitrogen content in BSFL manure is approximately $3.5 \%$ and in synthetic fertilizer is approximately $12 \%$ (e.g., 12-12-12). To fertilize the same area of land, 3.5 times more black soldier fly manure will be required than synthetic fertilizer. The manure from BSFL is considered a valuable product and has corresponding environmental impacts from BSFL production. In the assumption, the allocation was made based on mass, and $1 \mathrm{~kg}$ of manure is produced from $1 \mathrm{~kg}$ BSFL. Also, other researchers have emphasized the potential biological as well as ecological advantages of insect manure in the context of their research projects which has been presented in a review article by Schmitt and Vries [45].

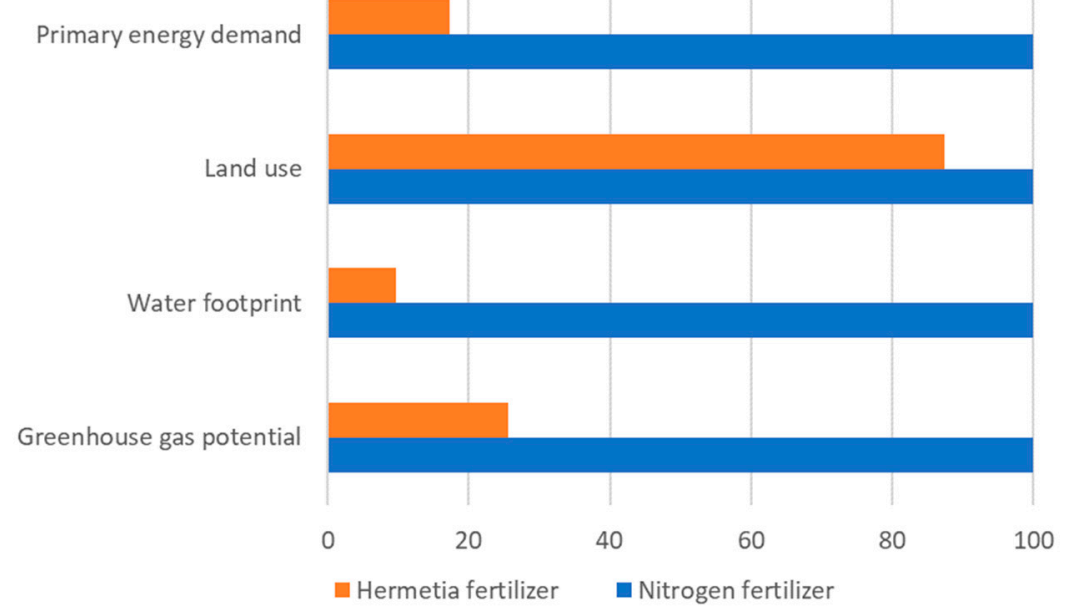

Figure 12. Environmental comparison between Hermetia manure and synthetic fertilizer to fertilize the same area of land. 
The Tilapia have special features in their development and behavior, which makes them an interesting model organism. They are particularly suitable for research because of their rapid growth, their ability to reproduce in captivity and also their high tolerance to environmental influences such as temperature and oxygen content of the water, their resistance to stress and diseases and their lack of requirements for artificial feed.

Supplementary Materials: The following are available online at https://www.mdpi.com/article/10. 3390/su13137371/s1. The (blank) questionnaire is enclosed as an excel File S1: Sample questionnaire.

Author Contributions: The conceptualization of the idea is given by D.S. and R.R. and methodology is suggested and chosen by D.O. and S.G. All the formal analysis of the data is done by D.O. and S.G. The research resources in terms of experiments and data generation were taken care of by J.L., A.M., D.H. and J.D. The data curation is done by D.O. and S.G. The original draft manuscript is written by S.G. while D.O. reviewed and edited it. Visualization is performed by D.O. and S.G. under the supervision of D.S. and H.O.G. The project is administered by D.S. All the authors and co-authors actively participated in funding acquisition and validation of the replication/reproducibility of results and research outputs. All authors have read and agreed to the published version of the manuscript.

Funding: This research was funded by the German Federal Ministry of Education and Research in the framework of the project "Lemna-Hermetia" ("KMU-innovativ" funding initiative, funding code 033RK048E).

Institutional Review Board Statement: Notification of the killing of vertebrates for scientific purposes according to Clause 4 Point 3 of Tierschutzgesetz (Animal Protection Act); name of the project: removal of organs to clarify the physiological constitution of tilapia after feeding with LH pellets.

Informed Consent Statement: Not applicable.

Data Availability Statement: Data available on request due to restrictions e.g., privacy or ethical. The data presented in this study are available on request from the corresponding author. The data are not publicly available due to data privacy policy of the companies involved in this study.

Conflicts of Interest: The authors declare no conflict of interest. The funders had no role in the design of the study; in the collection, analyses, or interpretation of data; in the writing of the manuscript, or in the decision to publish the results.

\section{References}

1. Cai, J.; Zhou, X. FAO Aquaculture Newsletter; Food and Agriculture Organization of the United Nations: Rome, Italy, 2019.

2. Food and Agriculture Organization of the United Nations. Aquaculture. Available online: http://www.fao.org/fishery/aquacul ture/en (accessed on 22 March 2021).

3. Edwards, O.; Bicknell, B.; Ford, J.; Yiu, B.; Blecher, M.; Mulvaney, W. Aquaculture Methods. Good Fish Bad Fish. Available online: http:/ / goodfishbadfish.com.au/?page_id=33 (accessed on 8 June 2021).

4. Aubin, J.; Papatryphon, E.; Werf, H.M.; Chatzifotis, S. Assessment of the environmental impact of carnivorous finfish production systems using life cycle assessment. J. Clean. Prod. 2009, 17, 354-361. [CrossRef]

5. Ayer, N.; Tyedmers, P.H. Assessing alternative aquaculture technologies: Life cycle assessment of salmonid culture systems in Canada. J. Clean. Prod. 2009, 17, 362-373. [CrossRef]

6. Iribarren, D.; Moreira, M.T.; Feijoo, G. Revisiting the Life Cycle Assessment of mussels from a sectorial perspective. J. Clean. Prod. 2010, 18, 101-111. [CrossRef]

7. ISO. ISO 14040:2006_Environmental Management_Life Cycle Assessment_Principles and Framework; International Organization for Standardization: Geneva, Switzerland, 2006.

8. ISO. ISO 14044:2006-Environmental Management_Life Cycle Assessment_Requirements and Guidelines; International Organization for Standardization: Geneva, Switzerland, 2006.

9. Iles, A. Making the seafood industry more sustainable: Creating production chain transparency and accountability. J. Clean. Prod. 2007, 15, 577-589. [CrossRef]

10. Ayer, N.; Côté, R.P.; Tyedmers, P.H.; Willison, J.M. Sustainability of seafood production and consumption: An introduction to the special issue. J. Clean. Prod. 2009, 17, 321-324. [CrossRef]

11. Belghit, I.; Liland, N.S.; Gjesdal, P.; Biancarosa, I.; Menchetti, E.; Li, Y.; Waagbo, R.; Krogdahl, Å.; Lock, E.-J. Black soldier fly larvae meal can replace fish meal in diets of sea-water phase Atlantic salmon (Salmo salar). Aquaculture 2019, 503, 609-619. [CrossRef]

12. Stadtlander, T.; Stamer, A.; Buser, A.; Wohlfahrt, J.; Leiber, F.; Sandrock, C. Hermetia illucens meal as fish meal replacement for rainbow trout on farm. J. Insects Food Feed. 2017, 3, 165-175. [CrossRef] 
13. Chakrabarti, R.; Clark, W.D.; Sharma, J.G.; Goswami, R.K.; Shrivastav, A.K.; Tocher, D. Mass Production of Lemna minor and Its Amino Acid and Fatty Acid Profiles. Front. Chem. 2018, 6, 479. [CrossRef]

14. Sharma, J.G.; Kumar, A.; Saini, D.; Targay, N.L.; Khangembam, B.K.; Chakrabarti, R. In vitro digestibility study of some plant protein sources as aquafeed for carps Labeo rohita and Cyprinus carpio using pH-Stat method. Indian J. Exp. Biol. 2016, 54, 606-611. [PubMed]

15. Leng, R.A.; Stambolie, J.H.; Bell, R. Duckweed-A potential high-protein feed resource for domestic animals and fish. Livest. Res. Rural Dev. 1995, 7, 36.

16. Muhlberg, H. The Complete Guide to Water Plants; E. P. Publishing Ltd.: Leipzig, Germany, 1982.

17. Huxley, A. The New Royal Horticultural Society Dictionary of Gardening; MacMillan Press: New York, NY, USA, 1992.

18. Kuppusamy, G.; Kong, C.K.; Segaran, G.C.; Tarmalingam, E.; Herriman, M.; Ismail, M.F.; Khan, T.M.; Low, L.E.; Goh, B.-H. Hummingbird-Leaves-Reared Black Soldier Fly Prepupae: Assessment of Nutritional and Heavy Metal Compositions. Biology 2020, 9, 274. [CrossRef] [PubMed]

19. Rumpold, B.A.; Schlüter, O.K. Potential and challenges of insects as an innovative source for food and feed production. Innov. Food Sci. Emerg. Technol. 2013, 17, 1-11. [CrossRef]

20. TROVET. Hypoallergenic (Insect) I IPD. (TROVET). Available online: https://www.trovet.com/product/hypoallergenic-insect-d og/ (accessed on 20 April 2021).

21. Lei, X.; Kim, T.; Park, J.; Kim, I. Evaluation of Supplementation of Defatted Black Soldier Fly (Hermetia illucens) Larvae Meal in Beagle Dogs. Ann. Anim. Sci. 2019, 19, 767-777. [CrossRef]

22. European Commission. (25. May 2017). EUR-Lex Access to European Union Law. Available online: https://eur-lex.europa.eu/le gal-content/EN/TXT/PDF/?uri=CELEX:32017R0893\&from=EN (accessed on 20 April 2021).

23. Lozano, S.; Iribarren, D.; Moreira, M.T.; Feijoo, G. The link between operational efficiency and environmental impacts: A joint application of Life Cycle Assessment and Data Envelopment Analysis. Sci. Total Environ. 2009, 407, 1744-1754. [CrossRef]

24. Lozano, S.; Iribarren, D.; Moreira, M.T.; Feijoo, G. Environmental impact efficiency in mussel cultivation. Resour. Conserv. Recycl. 2010, 54, 1269-1277. [CrossRef]

25. Iribarren, D.; Moreira, M.T.; Feijoo, G. Life Cycle Assessment of mussel culture. In Mussels: Anatomy, Habitat and Environmental Impact (S. 357-378); McGevin, L.E., Ed.; Nova Science Publishers: New York, NY, USA, 2011.

26. European Commission. Commission Regulation (EU) 2017/893 of 24 May 2017 Amending Annexes I and IV to Regulation (EC) No 999/2001 of the European Parliament and of the Council and Annexes X, XIV and XV to Commission Regulation (EU) No 142/2011 on processed animal protein. Off. J. Eur. Union. Available online: https://op.europa.eu/en/publication-detail/-/publi cation/d07e2398-410c-11e7-a9b0-01aa75ed71a1 (accessed on 20 April 2021).

27. Smetana, S.; Palanisamy, M.; Mathys, A.; Heinz, V. Sustainability of insect use for feed and food: Life Cycle Assessment perspective. J. Clean. Prod. 2016, 137, 741-751. [CrossRef]

28. Fusi, A.; Bacenetti, J.; Fiala, M.; Azapagic, A. Life Cycle Environmental Impacts of Electricity from Biogas Produced by Anaerobic Digestion. Front. Bioeng. Biotechnol. 2016, 4, 1-17. [CrossRef] [PubMed]

29. Roffeis, M.; Almeida, J.; Wakefield, M.E.; Valada, T.R.A.; Devic, E.; Koné, N.; Kenis, M.; Nacambo, S.; Fitches, E.C.; Koko, G.K.D.; et al. Life Cycle Inventory Analysis of Prospective Insect Based Feed Production in West Africa. Sustainability 2017, 9, 1697. [CrossRef]

30. Oonincx, D.G.; Boer, I.J. Environmental Impact of the Production of Mealworms as a Protein Source for Humans-A Life Cycle Assessment. PLoS ONE 2012, 7, e51145. [CrossRef]

31. Huis, A.V.; Itterbeeck, J.V.; Klunder, H.; Mertens, E.; Halloran, A.; Muir, G.; Vantomme, P. Edible Insects: Future Prospects for Food and Feed Security; Food and Agriculture Organization of the United Nations: Rome, Italy, 2013.

32. Thévenot, A.; Rivera, J.L.; Wilfart, A.; Maillard, F.; Hassouna, M.; Senga-Kiesse, T.; Le Féon, S.; Aubin, J. Mealworm meal for animal feed: Environmental assessment and sensitivity analysis to guide future prospects. J. Clean. Prod. 2018, 170, 1260-1267. [CrossRef]

33. Salomone, R.; Saija, G.; Mondello, G.; Giannetto, A.; Fasulo, S.; Savastano, D. Environmental impact of food waste bioconversion by insects: Application of Life Cycle Assessment to process using Hermetia illucens. J. Clean. Prod. 2017, 140, 890-905. [CrossRef]

34. Rebello, R.Z.; Lima, M.T.W.D.C.; Yamane, L.H.; Siman, R. Characterization of end-of-life LED lamps for the recovery of precious metals and rare earth elements. Resour. Conserv. Recycl. 2020, 153, 104557. [CrossRef]

35. Wernet, G.; Bauer, C.; Steubing, B.; Reinhard, J.; Moreno-Ruiz, E.; Weidema, B. The ecoinvent database version 3 (part I): Overview and methodology. Int. J. Life Cycle Assess. 2016, 21, 1218-1230. [CrossRef]

36. Ruiz-Salmón, I.; Laso, J.; Margallo, M.; Villanueva-Rey, P.; Rodríguez, E.; Quinteiro, P.; Dias, A.C.; Almeida, C.; Nunes, M.L.; Marques, A.; et al. Life cycle assessment of fish and seafood processed products - A review of methodologies and new challenges. Sci. Total Environ. 2021, 761, 144094. [CrossRef] [PubMed]

37. Samuel-Fitwi, B.; Meyer, S.; Reckmann, K.; Schroeder, J.P.; Schulz, C. Aspiring for environmentally conscious aquafeed: Comparative LCA of aquafeed manufacturing using different protein sources. J. Clean. Prod. 2013, 52, 225-233. [CrossRef]

38. Smárason, B.Ö.; Ögmundarson, Ó.; Ârnason, J.; Bjornsdottir, R.; Davíðsdóttir, B. Life Cycle Assessment of Icelandic Arctic Char Fed Three Different Feed Types. Turk. J. Fish. Aquat. Sci. 2017, 17, 79-90. [CrossRef]

39. Mohedano, R.A.; Costa, R.H.; Tavares, F.A.; Filho, P.B. High nutrient removal rate from swine wastes and protein biomass production by full-scale duckweed ponds. Bioresour. Technol. 2012, 112, 98-104. [CrossRef] 
40. Bonanno, G.; Vymazal, J.; Cirelli, G.L. Translocation, accumulation and bioindication of trace elements in wetland plants. Sci. Total. Environ. 2018, 631-632, 252-261. [CrossRef]

41. Olette, R.; Couderchet, M.; Biagianti, S.; Eullaffroy, P. Toxicity and removal of pesticides by selected aquatic plants. Chemosphere 2008, 70, 1414-1421. [CrossRef]

42. Matamoros, V.; Nguyen, L.X.; A Arias, C.; Salvado, V.; Brix, H. Evaluation of aquatic plants for removing polar microcontaminants: A microcosm experiment. Chemosphere 2012, 88, 1257-1264. [CrossRef]

43. Ergen, Ş.F.; Tunca, E. Üçüncü Nanotoxicity modelling and removal efficiencies of ZnONP. Int. J. Phytoremediation 2018, 20, 16-26. [CrossRef] [PubMed]

44. Ekperusi, A.O.; Sikoki, F.D.; Nwachukwu, E.O. Application of common duckweed (Lemna minor) in phytoremediation of chemicals in the environment: State and future perspective. Chemosphere 2019, 223, 285-309. [CrossRef] [PubMed]

45. Schmitt, E.; de Vries, W. Potential benefits of using Hermetia illucens frass as a soil amendment on food production and for environmental impact reduction. Curr. Opin. Green Sustain. Chem. 2020, 25, 100335. [CrossRef] 